\section{The Fine Structure of Bone}

X-RAX crystallographic studies by Engström and his collaborators ${ }^{1,2}$ have shown that the apatite crystallites of bone have linear dimensions of about $220 \mathrm{~A} . \times 65 \mathrm{~A}$. The crystals were aligned with their long axis parallel to the collagen fibre axis, and it was suggested that there may be three such inorganic crystals for each $640 \mathrm{~A}$. period of the collagen fibril. In a recent communication, Fernández-Morán and Engström" observed a "predominance of rod- or needle-shaped apatite particles $30-40 \mathrm{~A}$. wide and about $200 \mathrm{~A}$. long" in thin sections of bone by means of electron microscopy. This result is in reasonable agreement with those obtained by X-ray diffraction; but no evidence is offered that the regions of higher density present in the micrographs (which appear to have reproduced badly) were in fact due to apatite. Nor is it clear whether electron microscopy has provided any further evidence as to the manner of alignment of the particles, for Robinson and Watson ${ }^{4}$ have identified apatite in thin sections of bone by means of electron diffraction, and have indicated that the particles were deposited on the 'doublet' band region of the period of the fibril.

Electron microscopy and X-ray diffraction, how. ever, have not given unequivocal results regarding the site of the apatite particles; but work in this Laboratory has clarified the position to some extent ${ }^{5}$. In this work transverse and longitudinal sections of undecalcified embryonic avian bone were cut with a glass knife, and viewed in a modified MetropolitanVickers (E.M.III) electron microscope. Densitometer traces of electron micrographs of newly formed osteogenic fibrils demonstrated at least five bands and five interbands within a main period of the collagen fibril. At an early stage of calcification, very dense particles, of less than $100 \mathrm{~A}$. in size, became localized in a ring between the $d$ and $a b$ bands of the main period, that is, in the major region of indentation of the period (Fig. 1). In transverse sections of the appropriate part of the fibrils, the particles were seen to be irregular in outline, were about $100 \mathrm{~A}$. apart, and numbered up to ten per ring.

Measurements of the Bragg spacings of powder diffraction patterns, obtained by electron diffraction of such sections, were in close agreement with those

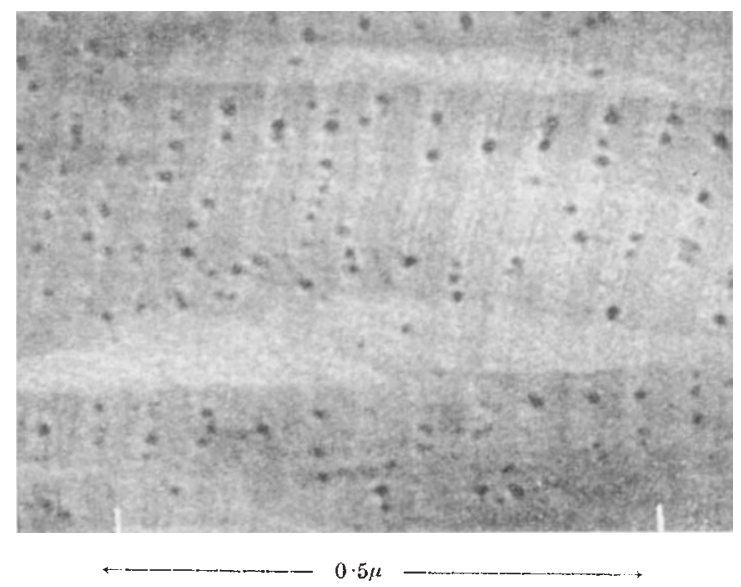

Fig. 1. A section of periosteal bone from a 16-day embryo, particles are localized in one interband of each period, namely, between the $d$ and $a b$ bands. $\times 110,000$ obtained from a control specimen of hydroxyapatite. It is therefore considered that these particles are to be identified with the apatite component of bone. There was no clear evidence, however, from either electron microscopy or electron diffraction, of any preferred orientation of the particles with respect to the fibre axis. The observation on embryonic bone of the localization of dense apatite particles between the $d$ and $a b$ bands is precise, and it is believed that such clarity of deposition has not been recorded in previous work. This finding may also have a bearing on the mechanism by means of which the apatite crystals become preferentially orientated with their $c$-axis parallel to the collagen fibre axis already demonstrated by means of X-ray diffraction ${ }^{1}$.

S. FitTon JACKSON

J. T. RANDALL

Medical Research Council

Biophysics Research Unit,

Wheatstone Laboratory,

King's College,

London, W.C.2.

Sept. 6.

1 Engström, A., and Zetterström, R., Exp. Cell Res., 2, 268 (1951).

${ }^{2}$ Finean, J. B., and Engström, A., Biochim. Biophys. Acta, 11, 178 (1953). Cariström, D., and Finean, J. B., Biochim. Biophys. Acta, 13, $183(\mathbf{1 9 5 4 )}$. Carlström, D., Engstrồm, A., and Finean, J. B., Eleventh Symp. Soc. Exp. Med., 271, edit. Brown and Danielli (Camb. Univ. Press, 1955). Carlström, D., Acta Radiol., Supp. 121, Stockholm (1955). Engström, A., 1955 Ciba Found. and O'Connor Structure and Metabolism"

${ }^{3}$ Fernández-Morán, H., and Engström, A., Nature, 178, 495 (1956).

4 Robinson, R. A., and Watson, M. L., Anat. Rec., 114, 383 (1952). Robinson, R. A., and Watson, M. L., Trans. Macy Conf. Met. Int., 5, 72 (1953). Robinson, R. A., and Watson, M. L., Ann. N.Y. Acad. Sci., 60, 598 (1955)

"Fitton Jackson, S., and Randall, J., T., 1955 Ciba Found. Symp., "Bone Structure and Metabolism", 47, edit. Wolstenholme and Roy. Soc., B (in the press).

\section{The Lateral Rectus Muscle and Sixth Cranial Nerve in the Pig}

THE lateral rectus muscle and sixth nerve have been studied in four young pigs ranging in age from three to six weeks. Fixation of the orbital contents and brain stem was ensured by ante-mortem perfusions. The muscle was examined in frozen sections taken through longitudinal and transverse planes, and stained by the diammine silver ion technique ${ }^{1}$ A block of the brain stem extending from the upper medulla to mid-brain was treated by the Bielschowsky pyridine-silver process, and sections, namely, dorsoventral, longitudinal and transverse, were examined. The trunk of the sixth nerve was studied in preparations stained by hæmatoxylin and eosin and by methylene blue.

The volume of nerve in the lateral rectus was calculated to be approximately 9 per cent. Four main types of ending were observed in the muscle : (1) motor end-plates, found most abundantly in the posterior and middle thirds ; (2) muscle spindles of standard type, anteriorly placed and deep to the peripheral zone of small muscle fibres; (3) large numbers of longitudinal fibres connected by collaterals and ending freely in fine filaments on the muscle fibres; (4) tendon endings at the attachments of the muscle.

Nerve cells on the sixth nerve in man have been reported by Nicholson ${ }^{2}$. In two of our animals, a few small ganglia were observed adjacent to the fibres of the sixth nerve in the region of the cavernous sinus. 